\title{
A Survey on HIV, HCV, and HBV and Related Factors Among the Homeless Population, Southeast of Iran
}

\author{
Seyed Mohammad Hashemi Shahri (iD) ${ }^{1}$, Fatemeh Ansari-Moghadam (iD 1, " and Alireza Ansari \\ Moghadam (10) ${ }^{2}$ \\ 'Zahedan University of Medical Sciences, Zahedan, Iran \\ ${ }^{2}$ Health Promotion Research Center, Zahedan University of Medical Sciences, Zahedan, Iran \\ Corresponding author: Zahedan University of Medical Sciences, Zahedan, Iran. Email: fa.moghadam@yahoo.com
}

Received 2020 September 14; Revised 2020 December 12; Accepted 2020 December 19.

\begin{abstract}
Background: Homeless people are prone to sexually transmitted and blood-borne infectious diseases such as hepatitis B, hepatitis C, and HIV due to their risky behaviors and low awareness of various diseases.

Objectives: Thus, the present research aimed to examine the epidemiologic patterns of HBV, HCV, HIV, and related factors among the homeless population of Zahedan in 2019.

Methods: A cross-sectional study was conducted on a total of 329 homeless people. Eligible people were selected using a convenience sampling method from homeless individuals residing in care centers affiliated with the Welfare Organization and the Health Deputy of Zahedan University of Medical Sciences. Data on the demographic and behavioral characteristics of the cases were collected through a structured questionnaire completed in face-to-face interviews. A $10 \mathrm{cc}$ blood sample was taken from each of the cases for serological tests of hepatitis B, hepatitis C, and HIV. The test results and collected data were entered in SPSS16 software. Logistic regression analysis and chi-square tests were used to analyze the data.

Results: The majority of the cases (84\%) were males, and 59\% were in the age-group of 35 - 50 years. Of the subjects, $93 \%$ had a history of drug abuse, $74 \%$ reported a history of smoking, and $45 \%$ had tattoos. The prevalence of hepatitis C, hepatitis B, and HIV was 13\%, $2.7 \%$, and $0.3 \%$, respectively (only one case of HIV was identified). In a multi-variate model, imprisonment history [OR $=2.32(1.08$ $4.98)]$, history of sexual abuse $[\mathrm{OR}=3.73(1.36-10.26)]$, being widowed or divorced [OR $=2.83,(1.21-6.64)]$, and history of injection with shared needles and syringes $[\mathrm{OR}=5.11(1.97-13.28)]$ remained the predicting factors of hepatitis $\mathrm{C}$.

Conclusions: Based on the obtained results of the study, homeless people are more prone to infections with HCV, HBV, and HIV due to their risky behaviors. Therefore, a need is highlighted for preventive interventions and developing the level of health literacy in this group regarding behaviors contributing to the aforementioned infections.
\end{abstract}

Keywords: Homeless People, HCV, HBV, HIV

\section{Background}

Hepatitis B, hepatitis C, and human immunodeficiency viruses are among the worldwide public health challenges. According to the World Health Organization, 71 million people are infected with chronic hepatitis $\mathrm{C}$, and a large part of its prevalence (2.3\%) is observed in the Eastern Mediterranean region. Most hepatitis $C$ cases are asymptomatic, and the majority of the mortalities are due to chronic forms of hepatitis $C$ such as cirrhosis and hepatocellular carcinoma (1). Over the world, 257 million people are infected with chronic hepatitis $B$, the prevalence of which is reported to be $3.3 \%$ in the Eastern Mediterranean area (2). According to a 2018 census, the number of HIV patients was 37.9 million worldwide (3). The prevalence of hepatitis B and C in the general population of Iran, accord- ing to the literature, is $2.2 \%$ and $0.6 \%$, respectively $(4,5)$. The number of HIV patients in Iran has been reported to be 61,000 (6). People with chronic conditions have higher rates of poor psychological and psychiatric disorders that may impair their quality of life (7). Due to the transmission modes of these diseases, people who are involved in risky behaviors are more exposed to the risk of being infected by such diseases, and their diagnosis and treatment are of great importance.

Being homeless is a complication contributing to public hygiene and social issues around the world, resulting in behavioral, social, and environmental risk factors (8, 9). Since homeless people have a lower literacy level, economic status, and nutritional health, tending to become involved in risky sexual behaviors and using injectable 
drugs, they are more prone to infections transmitted by the blood, such as hepatitis B, hepatitis C, and AIDS $(10,11)$. Morbidity and mortality also tend to be higher among the homeless $(12,13)$. The worldwide prevalence of HIV, tuberculosis, and hepatitis $\mathrm{C}$ among homeless people has been reported to be $0.3-21.1 \%, 0.2-7.7 \%$, and $3.9-36.2 \%$, respectively (14). The prevalence of hepatitis B, hepatitis C, and HIV among homeless people was reported as $2.6 \%, 23.3 \%$, and 3.4\%, respectively, in Tehran, the capital of Iran (15). This number was also reported as $0.98 \%, 31.27 \%$, and $6.51 \%$, respectively, in Lorestan province, in the west of Iran (16).

\section{Objectives}

This study was conducted to examine the epidemiologic patterns of HBV, HCV, and HIV, and related factors in Zahedan due to a lack of data regarding the prevalence of blood-borne infectious diseases among homeless people in the south-eastern regions of Iran. The study would provide useful data for health policymakers to design evidence-based interventions towards reducing the risk of disease transmission in this risky group.

\section{Methods}

A cross-sectional study was conducted on 329 homeless people in Zahedan, Southeast of Iran, from March to August 2019. The sample size was estimated using $\alpha=0.05$, $\mathrm{d}=0.05$, and the following formula:

$$
\begin{aligned}
N & =\frac{Z^{2} P(1-P)}{d^{2}} \\
& =\frac{3.84(0.31)(0.69)}{(0.05)^{2}} \\
& =329
\end{aligned}
$$

Homeless people were eligible to participate if they were 18-years-old or over, residing in homeless shelters, or referring to drop-in centers. The exclusion criteria included the disagreement of the participant with the study, being under the age of 18 , and refusing to do hepatitis B, $\mathrm{C}$, and HIV tests. All Helsinki declaration principles were applied in this study, and the cases were examined after the research proposal was approved by the Ethics Committee of Zahedan University of Medical Sciences (code: IR.ZAUMS.REC.1397.434).

A convenience sampling method was used to include eligible individuals from homeless people residing in three shelters and those who were referred to eight dropin centers (DIC) affiliated with Zahedan Welfare Organization and Zahedan University of Medical Sciences. To collect data, informed consent was obtained from all participants before being interviewed, and then, behavioral and demographic data were collected using a structured questionnaire through direct interviews under the supervision of a trained expert, accompanied by a local person familiar with the local language.

Blood samples of $10 \mathrm{cc}$ were taken from the cases by a trained laboratory expert and transferred under appropriate conditions to the Zahedan Blood Transfusion Organization. The samples were examined in the Blood Transfusion Organization for HBV, HCV, and HIV infections using the ELISA method. The HCV Ab positive tests were confirmed via the RIBA method, and the HIV Ab positive tests were confirmed by Western blotting. The data remained confidential. The obtained data were entered in SPSS 16 software and analyzed through the Chi-square and logistic regression (backward stepwise) tests. The P values under 0.05 were considered statistically significant.

\section{Results}

The present study surveyed 329 homeless people in Zahedan. The results indicate that $84 \%$ of the cases (270 people) were males, and $16 \%$ were females ( 59 people). In terms of age, $59 \%$ of the cases (195 people) were in the 35 - 50 years' age group. Around $60 \%$ of the cases (195 people) were illiterate or only had primary education. A majority of the participants also reported a history of drug abuse (93\%), $74 \%$ reported a history of smoking, $72 \%$ had received unhygienic and unofficial dental health services, $47 \%$ had a history of imprisonment, and $45 \%$ had a history of getting tattoos. The prevalence of hepatitis C, hepatitis B, and HIV among the participants was also determined to be $13 \%, 2.7 \%$, and $0.3 \%$, respectively (only one case of HIV was identified).

As Table 1 demonstrates, the prevalence of hepatitis $C$ increased with age, so that the prevalence changed from $3 \%$ in the participants aged 18 - 34 to $25 \%$ in participants aged over 50 . The hepatitis B prevalence indicated no specific trend, with $4 \%$ prevalence in participants aged $35-50$ (the highest prevalence) and $1 \%$ in participants aged over 50 (the lowest prevalence). Of the participants, $40(15 \%)$ males and four (7\%) females were diagnosed with hepatitis C. The prevalence of hepatitis B was also shown to be higher among males (3\% vs. $2 \%$ ). Only one case (female) of HIV was identified. Additionally, the prevalence of hepatitis B, C, and HIV indicated that cases with higher literacy had a lower chance of hepatitis $C$ infection (18\% in illiterate participants compared to $7 \%$ in those with academic education). Similarly, the hepatitis B prevalence decreased from $4 \%$ in illiterate participants to $2 \%$ in participants with secondary education and $0 \%$ in those with academic education (Table 1 ).

Regarding the risk factors for the aforementioned infections, the results demonstrated in Table 2 indicate that the percentage of people suffering from hepatitis $C$ was significantly $(\mathrm{P}=0.032)$ higher $(10 \%)$ in participants who had 


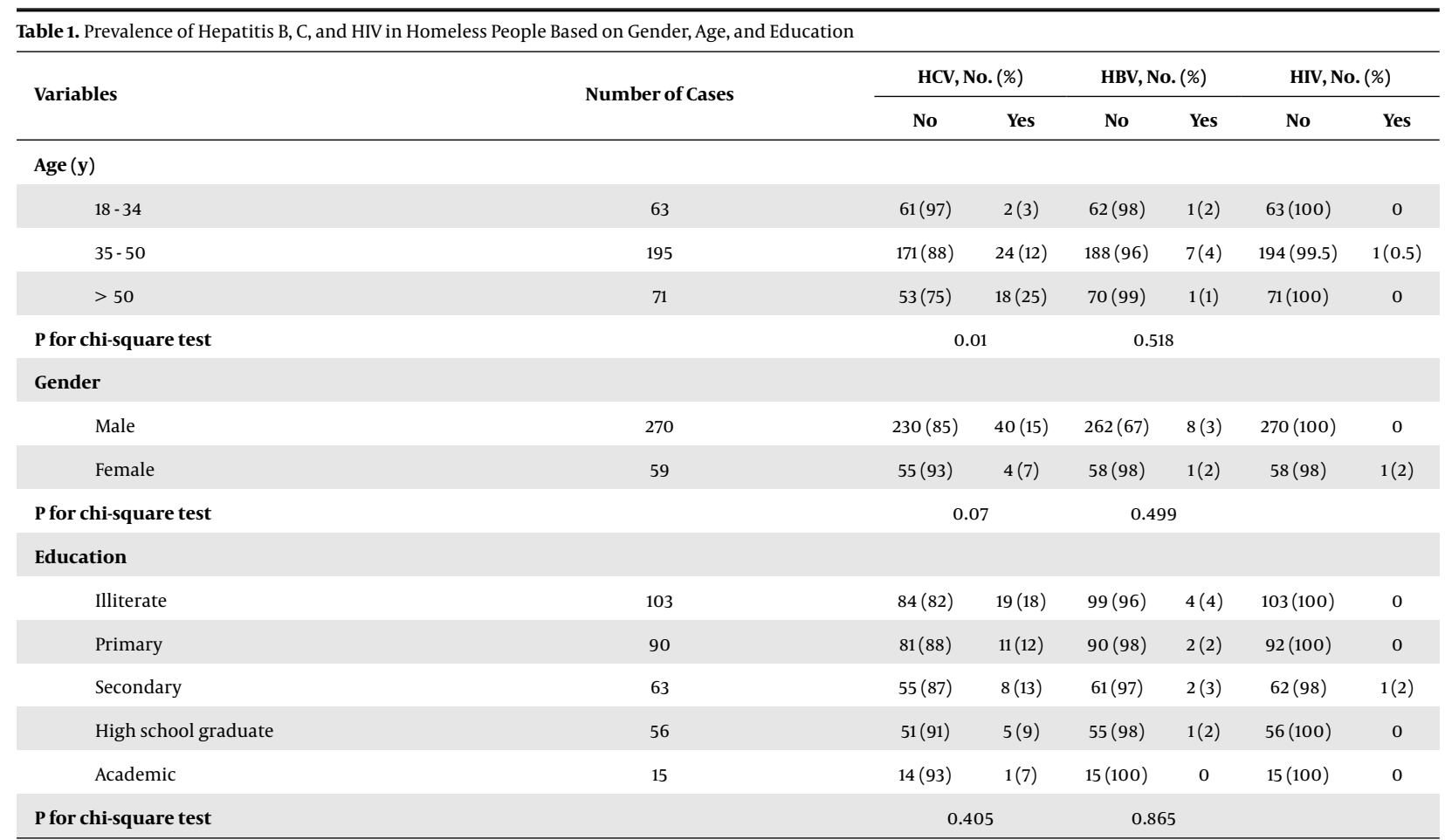

tattoos. Hepatitis B was also higher in cases that had a history of getting tattoos than in those without this history (0.04 vs. $0.02, P=0.162$ ), which was not statistically significant.

Additionally, it was observed that hepatitis $\mathrm{C}$ diagnosis was significantly $(\mathrm{P}<0.001)$ higher in people who had injections by sharing syringes (50\%) than in people without this history (10\%). The hepatitis B prevalence was also higher in people who had a history of injections by sharing syringes; however, the difference was not statistically significant. The hepatitis $C$ prevalence was remarkably higher in those who did not have a history of receiving unhygienic and unofficial dental health services than in those who had received such services $(\mathrm{P}=0.011)$. The hepatitis $B$ prevalence was not statistically significant between the two aforementioned groups ( 0.03 vs. $0.02, \mathrm{P}=0.534$ ).

Data demonstrated in Table 2 indicate that the percentage of hepatitis $\mathrm{C}$ infection was significantly higher $(\mathrm{P}=$ 0.011 ) in those with a history of sexual abuse (38\%) than in those with no such history (11\%). Of the participants, 50\% (one person) with a hemophilia history and 25\% (one person) with a thalassemia history were also diagnosed with HCV. All Cases with a hemophilia history (two persons), had hepatitis B.. One patient diagnosed with HIV had no history of other diseases (Table 2).

As presented in Table 3, there was a significant relationship between the family history of infection and the risk of hepatitis $\mathrm{B}(\mathrm{P}=0.002)$ and hepatitis $\mathrm{C}(\mathrm{P}<0.001)$ in home- less people. The prevalence of hepatitis $C$ in those with imprisonment history (21\%) was significantly higher $(\mathrm{P}<$ 0.001) than that in those with no such history (7\%). The prevalence of hepatitis B was almost similar across the two aforementioned groups.

The relationships between the history of smoking and hepatitis $\mathrm{B}$ and $\mathrm{C}$ are shown in Table 3. The prevalence of hepatitis $C$ in participants with a history of smoking was higher than that in those who did not have a history of smoking; however, this difference was not statistically significant. Additionally, the prevalence of hepatitis B was similar in the two aforementioned groups. A history of drug abuse was also revealed to have no significant impact on the prevalence of hepatitis B and C.

The history of illicit sex had an impact on the prevalence of hepatitis B and C. Statistically, the difference in the prevalence of hepatitis B and C between the two groups of participants with and without a history of illicit sex was not significant. Hepatitis $C$ was significantly $(P<0.001)$ more prevalent in those who had a history of drug injection, as opposed to those with no such history. The prevalence of hepatitis B was also higher in those with a history of drug injection, but the difference was not statistically significant (Table 3).

After using a multivariate logistic regression model (backward stepwise), only variables including a history of imprisonment, sexual abuse, injection by sharing syringes, and being married remained in the model (Table 


\begin{tabular}{|c|c|c|c|c|c|}
\hline \multirow{2}{*}{ Indicators } & \multirow{2}{*}{ Number of Cases } & \multicolumn{2}{|c|}{ HCV, No. (\%) } & \multicolumn{2}{|c|}{ HBV, No. (\%) } \\
\hline & & No & Yes & No & Yes \\
\hline \multicolumn{6}{|l|}{ Tattoo $(s)$} \\
\hline Yes & 148 & $12(82)$ & $26(18)$ & $142(96)$ & $6(4)$ \\
\hline No & 181 & $163(90)$ & $18(10)$ & $178(98)$ & $3(2)$ \\
\hline$P$ for chi-square test & & \multicolumn{2}{|c|}{0.032} & \multicolumn{2}{|c|}{0.162} \\
\hline \multicolumn{6}{|c|}{ Sharing syringes/needles } \\
\hline Yes & 24 & $12(50)$ & $12(50)$ & $22(92)$ & $2(8)$ \\
\hline No & 292 & $262(90)$ & $30(10)$ & $286(96)$ & $6(2)$ \\
\hline Cannot recall & 13 & $11(85)$ & $2(15)$ & $12(92)$ & $1(8)$ \\
\hline$P$ for chi-square test & & \multicolumn{2}{|c|}{$<0.001$} & \multicolumn{2}{|c|}{0.104} \\
\hline \multicolumn{6}{|c|}{ Blood transfusion history } \\
\hline Yes & 33 & $25(76)$ & $8(24)$ & $31(94)$ & $2(6)$ \\
\hline No & 296 & $260(88)$ & $36(12)$ & $289(98)$ & $7(2)$ \\
\hline$P$ for chi-square test & & \multicolumn{2}{|c|}{0.145} & \multicolumn{2}{|c|}{0.462} \\
\hline \multicolumn{6}{|c|}{ History of receiving unofficial dental health services } \\
\hline Yes & 239 & $214(89)$ & $25(11)$ & $232(97)$ & $7(3)$ \\
\hline No & 90 & $71(79)$ & $19(21)$ & $88(98)$ & $2(2)$ \\
\hline$P$ for chi-square test & & \multicolumn{2}{|c|}{0.011} & \multicolumn{2}{|c|}{0.534} \\
\hline \multicolumn{6}{|c|}{ History of being sexually abused } \\
\hline Yes & 26 & $16(62)$ & $10(38)$ & $25(96)$ & $1(4)$ \\
\hline No & 303 & $269(89)$ & $34(11)$ & $295(97)$ & $8(3)$ \\
\hline$P$ for chi-square test & & \multicolumn{2}{|c|}{0.01} & \multicolumn{2}{|c|}{0.732} \\
\hline \multicolumn{6}{|c|}{ History of hemophilia, thalassemia, or dialysis } \\
\hline Yes & 10 & $8(80)$ & $2(20)$ & $8(80)$ & $2(20)$ \\
\hline No & 319 & $277(86.8)$ & $42(13.2)$ & $312(97.8)$ & $7(2.2)$ \\
\hline$P$ for chi-square test & & \multicolumn{2}{|c|}{0.53} & \multicolumn{2}{|c|}{0.001} \\
\hline
\end{tabular}

4). The odds of contracting hepatitis $C$ infection was 3.73 (95\% CI:1.36-10.26) higher in people with a history of being sexually abused than in those with no such history. Injection by sharing syringes was also revealed to increase the chance of hepatitis C by five times (95\% CI:1.97-13.28). Widowed or divorced participants also had a doubled chance (95\% CI: 1.21 - 6.64) of hepatitis C infection in comparison to married participants.

\section{Discussion}

The results of our study suggest that the prevalence of hepatitis C, HbsAg, and HIV among homeless people in Zahedan was $13 \%, 2.7 \%$, and $0.3 \%$, respectively. According to the World Health Organization, 71 million people suffer from chronic hepatitis $\mathrm{C}$ worldwide, which is most prevalent in the Eastern Mediterranean area (2.3\%); besides, $23 \%$ of new cases and 33\% of mortality cases have been in patients with intravenous injection (1).

The prevalence of hepatitis C was $13 \%$ in our study. Based on a meta-analysis study, the worldwide hepatitis C prevalence in homeless people is 3.9\% - 36.2\% (14). Studies conducted in Iran showed a prevalence of $31.27 \%$ in Lorestan, 23.3\% in Tehran, and 56\% in injection drug users in Arak (15-17). The present study suggests that the prevalence of hepatitis $C$ is lower in Zahedan than in other regions of Iran, but higher than in some regions in the world. Hepatitis $\mathrm{C}$ was also revealed to be more prevalent in our study participants than in the general population (0.6\%) of Iran (5). According to the literature, factors such as a low 


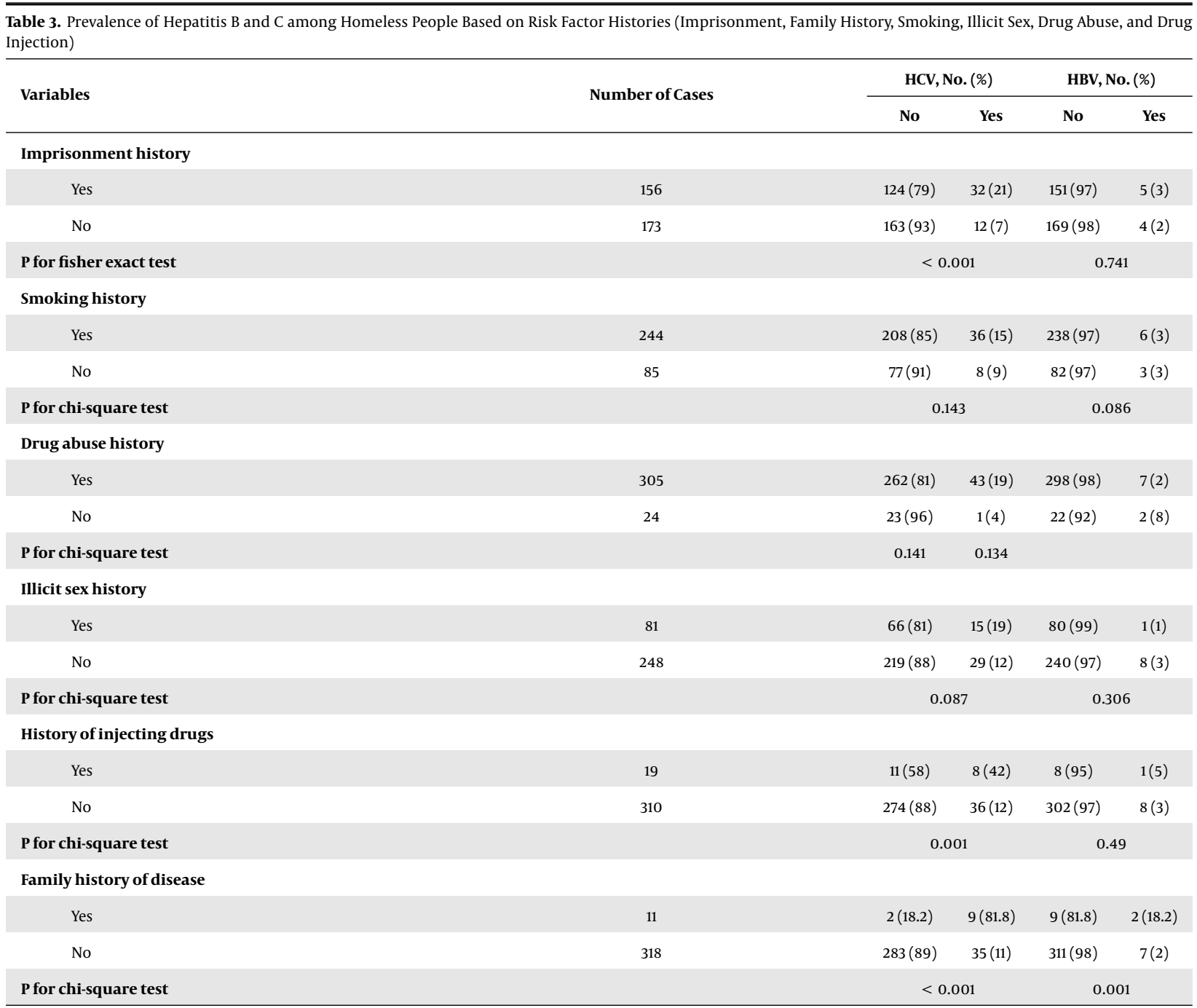

awareness level and high prevalence of risky behaviors in homeless people have led them to be more prone to hepatitis, HIV, and other sexually transmitted diseases $(18,19)$. Illicit drug injections and risky sexual behaviors increase the chance of homeless people getting infected with bloodborne diseases $(20,21)$, which can justify the higher prevalence of HCV among homeless people in Zahedan in comparison with the general population in Iran.

The present study discovered that the prevalence of HBsAg in homeless people of Zahedan was $2.7 \%$. This prevalence was revealed to be higher than that of other Iran provinces (16), such as Lorestan (0.98\%), and almost equal to the prevalence of hepatitis B in Tehran (2.6\%) (15). The prevalence of hepatitis B in the general population has been reported at 3.3\% in the Eastern Mediterranean region (2) and $2.2 \%$ in Iran (4), which is not different from the prevalence of hepatitis B in Zahedan. Co-infection of HBV and HCV was $0.6 \%$ in this study. Only one case of HIV(0.3\%) was reported in our study, while the prevalence of HIV infection was reported to be $0.3 \%-21.1 \%$ around the world (14), 6.5\% in Lorestan (16), 3.4\% in Tehran (15), and 19\% in Arak (17).

Establishing permanent homeless shelters and transient damage control centers (DIC) across the city of Zahedan, in addition to providing hot meals, clothes, free education, and consulting sessions regarding specific diseases such as HIV and hepatitis, and handing out free syringes to the homeless, have increased their awareness regarding risky behaviors, which might be the reason for the low prevalence of HIV, hepatitis B, and even hepatitis C in our study in comparison with that of other regions in Iran. The multivariate analysis revealed that the indicators of injection by sharing syringes, imprisonment history, history of sexual abuse, and being widowed or divorced contribute to the risk of hepatitis $\mathrm{C}$ infection. The overall prevalence of hepatitis C is $13.2 \%$ in imprisoned people (22) and $28 \%$ 


\begin{tabular}{|c|c|c|c|}
\hline Variable & Number of Cases & Hepatitis C Prevalence, No. (\%) & Odds Ratio, (95\% Confidence Interval) \\
\hline \multicolumn{4}{|l|}{ Imprisonment history } \\
\hline No & 173 & $12(6.9)$ & 1 \\
\hline Yes & 156 & $32(20.5)$ & $2.32(1.08-4.98)$ \\
\hline \multicolumn{4}{|l|}{ History of sexual abuse } \\
\hline No & 302 & $34(11.3)$ & 1 \\
\hline Yes & 26 & $10(38.5)$ & $3.73(1.36-10.26)$ \\
\hline \multicolumn{4}{|c|}{ History of injection with sharing syringes/needles } \\
\hline No & 292 & $30(10.3)$ & 1 \\
\hline Yes & 24 & $12(50)$ & $5.11(1.97-13.28)$ \\
\hline \multicolumn{4}{|l|}{ Marital status } \\
\hline Married & 170 & $16(9.4)$ & 1 \\
\hline Single & 94 & $13(13.8)$ & $1.08(0.45-2.60)$ \\
\hline Widowed or divorced & 65 & $15(23)$ & $2.83(1.21-6.64)$ \\
\hline
\end{tabular}

in Iranian prisoners (23). According to our results, imprisonment history led to a two-time increase in the chance of hepatitis $\mathrm{C}$. There is strong evidence that injection with used syringes is among the significant risk factors of HCV infection in prisoners (24). People with risky behaviors being gathered in enclosed environments, such as prisons, and prisoners' limitations of access to hygienic services and, therefore, reusing syringes, can increase the risk of hepatitis $\mathrm{C}$ infection in these inmates.

According to our results, reusing syringes increased the chance of hepatitis C by five times. Globally, 60 - 80\% of people with a history of intravenous injection are prone to hepatitis $C$ infection, mainly due to sharing needles and syringes (21). Limited access to harm-reduction interventions, unemployment, being deprived of sufficient income, and a low literacy level among homeless people, to which our cases were no exception, can lead to the use of previously used syringes which will, in turn, increase their risk of hepatitis $\mathrm{C}$ infection.

According to our results, the history of being sexually abused increased the chance of hepatitis $C$ infection by three times. Some studies suggest that hepatitis $C$ virus RNA found in the semen, vaginal discharges, saliva, and cervix smears indicates the chance of sexual transmission of this disease (25). Factors such as using illicit drugs after or before sexual intercourse, having multiple sexual partners, and co-occurrence of other sexually transmitted diseases are related to the chance of HCV transmission in vulnerable patients (26). Due to the lack of social support and strong family connections, homeless people are prone to risky sexual behaviors, as well as risky injections, which can justify the high hepatitis $C$ prevalence in our study. This relationship has also been mentioned in several other studies $(25,27)$.

Additionally, our study indicated that being widowed or divorced increases the chance of hepatitis $\mathrm{C}$ by two times, which can be a result of the different lifestyles of these people and the higher possibility of engaging in risky behaviors. Individuals without social support have greater difficulty in accessing health services, which tends to increase the risk of exposure to HCV and other pathogens.

One of our research limitations was that the information on risk factors was directly obtained from the participants. The authors tried to make up for this issue by confirming the information through consulting local people, shelter trustees, and drop-in centers.

The present study revealed that despite the existing interventions, homeless people are still prone to infectious diseases such as hepatitis B, hepatitis C, and HIV, due to a compromised immune system, poor nutrition and hygiene, and overcrowding in shelters. Particular activities that some homeless people engage in, such as survival sex or intravenous drug use, also increase the spread of disease. It is recommended that preventive measures such as treatment, hepatitis B vaccination, and screening be performed on the homeless. There is also a need for policymakers to increase the health literacy of the homeless regarding such risky behaviors.

\subsection{Conclusions}

According to the present research results, it can be inferred that the prevalence of HBV, HCV, and HIV infections and their risk factors are higher in homeless people than in others. To control the aforementioned infectious epidemics among the homeless, preventive interventions, education, and improving the level of health literacy regard- 
ing risky behaviors must be realized, on top of providing social support for homeless people in our country.

\section{Footnotes}

Authors' Contribution: Study concept and design, M.H.; Analysis and interpretation of data, A.A.; Drafting of the manuscript, F.A.; Critical revision of the manuscript for important intellectual content, M.H.; Statistical analysis, A.A.; Study supervision, M.H.

Conflict of Interests: The authors have no conflict of interest.

\section{Ethical Approval: IR.ZAMUS.REC.1397.434}

Funding/Support: This research was funded by the Zahedan University of Medical Sciences.

\section{References}

1. World Health Organization. Hepatitis C. Hepatitis: Fact sheets. Geneva, Switzerland: WHO; 2017, [updated 27 July 2020; cited 23 Jan]. Available from: https://www.who.int/en/news-room/fact-sheets/detail/ hepatitis-c.

2. World Health Organization. Hepatitis B. Hepatitis: Fact sheets. Geneva, Switzerland: WHO;2019, [updated 27 July 2020]. Available from: https: //www.who.int/en/news-room/fact-sheets/detail/hepatitis-b.

3. UNAIDS. Global HIV\& AIDS statistic, 2019 factsheet. Geneva, Switzerland: UNAIDS; 2019, [updated 30Jun 2020]. Available from: http://aidsinfo. unaids.org/.

4. Salehi-Vaziri M, Sadeghi F, Almasi Hashiani A, Gholami Fesharaki M, Alavian SM. Hepatitis B virus infection in the general population of Iran: An updated systematic review and meta-analysis. Hepat Mon. 2016;16(4). e35577. doi: 10.5812/hepatmon.35577. [PubMed: 27257428]. [PubMed Central: PMC4888501].

5. Mirminachi B, Mohammadi Z, Merat S, Neishabouri A, Sharifi AH, Alavian $\mathrm{SH}$, et al. Update on the prevalence of hepatitis $\mathrm{C}$ virus infection among Iranian general population: A systematic review and metaanalysis. Hepat Mon. 2017;17(2). doi: 10.5812/hepatmon.42291.

6. UNAIDS. Epidemiological factsheets on HIV/AIDS and Sexually Transmitted Disease. Geneva, Switzerland: UNAIDS; 2004. Available from: https:// data.unaids.org/publications/fact-sheets01/iran_en.pdf.

7. Moayedi F, Jashoonia Hormozi S, Tahamtan I. Mental health status of patients with HIV/AIDS in the south of Iran. Health Scope. 2015;4(2) doi: $10.17795 /$ ihealthscope-25796.

8. Badiaga S, Raoult D, Brouqui P. Preventing and controlling emerging and reemerging transmissible diseases in the homeless. Emerg Infect Dis. 2008;14(9):1353-9. doi: 10.3201/eid1409.080204. [PubMed: 18760000]. [PubMed Central: PMC2603102].

9. Ahmadkhaniha HR, Shariat SV, Torkaman-nejad S, Hoseini Moghadam MM. The frequency of sexual abuse and depression in a sample of street children of one of deprived districts of Tehran. J Child Sex Abus. 2007;16(4):23-35. doi: 10.1300/J070v16no4_02. [PubMed: 18032244].

10. Vahdani P, Hosseini-Moghaddam SM, Family A, Moheb-Dezfouli R. Prevalence of HBV, HCV, HIV and syphilis among homeless subjects older than fifteen years in Tehran. Arch Iran Med. 2009;12(5):483-7. [PubMed: 19722771].

11. Fryling LR, Mazanec P, Rodriguez RM. Barriers to homeless persons acquiring health insurance through the affordable care act.J Emerg Med. 2015;49(5):755-62 e2. doi: 10.1016/j.jemermed.2015.06.005. [PubMed: 26281811]. [PubMed Central: PMC4633336].
12. Geddes JR, Fazel S. Extreme health inequalities: Mortality in homeless people. Lancet. 2011;377(9784):2156-7. doi: 10.1016/S01406736(11)60885-4. [PubMed: 21676455].

13. Feodor Nilsson S, Hjorthoj CR, Erlangsen A, Nordentoft M. Suicide and unintentional injury mortality among homeless people: A Danish nationwide register-based cohort study. Eur J Public Health. 2014;24(1):50-6. doi: 10.1093/eurpub/ckt025. [PubMed: 23482619].

14. Beijer U, Wolf A, Fazel S. Prevalence of tuberculosis, hepatitis $C$ virus, and HIV in homeless people: a systematic review and meta-analysis. Lancet Infect Dis. 2012;12(11):859-70. doi: 10.1016/S1473-3099(12)70177-9. [PubMed: 22914343]. [PubMed Central: PMC3494003].

15. Amiri FB, Gouya MM, Saifi M, Rohani M, Tabarsi P, Sedaghat A, et al. Vulnerability of homeless people in Tehran, Iran, to HIV, tuberculosis and viral hepatitis. PLoS One. 2014;9(6). e98742. doi: 10.1371/journal.pone.0098742. [PubMed: 24896247]. [PubMed Central: PMC4045893].

16. Doosti-Irani A, Mokhaeri H, Chegini Sharafi A, Aghasadeghi MR, Hajimiragha M, Saki M, et al. Prevalence of HIV, HBV, and HCV and related risk factors amongst male homeless people in Lorestan province, the west of Iran. J Res Health Sci. 2017;17(1). e00373. [PubMed: 28413168].

17. Ramezani A, Amirmoezi R, Volk JE, Aghakhani A, Zarinfar N, McFarland W, et al. HCV, HBV, and HIV seroprevalence, coinfections, and related behaviors among male injection drug users in Arak, Iran. AIDS Care. 2014;26(9):1122-6. doi: 10.1080/09540121.2014.882485. [PubMed: 24499303]. [PubMed Central: PMC4065214].

18. Akhtarkhavari T, Naderloo B. [The prevalence of risky sexual behaviors and awareness of STDS among temporary residents of homeless shelters in Tehran]. Alborz University Medical Journal. 2019;8(3):225-35. Persian. doi: 10.29252/aums.8.3.225.

19. Fallahi H, Daryoushi S. Risk factors and prevalence of the sexually transmitted infections including HIV, syphilis and hepatitis among men who have sex with men. Hakim Research Journal. 2015;18(2):13945.

20. Dinenno EA, Oster AM, Sionean C, Denning P, Lansky A. Piloting a system for behavioral surveillance among heterosexuals at increased risk of HIV in the United States. Open AIDS J. 2012;6:169-76. doi: 10.2174/1874613601206010169. [PubMed: 23049666]. [PubMed Central: PMC3462336].

21. Nelson PK, Mathers BM, Cowie B, Hagan H, Des Jarlais D, Horyniak D, et al. Global epidemiology of hepatitis $B$ and hepatitis $C$ in people who inject drugs: Results of systematic reviews. Lancet. 2011;378(9791):57183. doi: 10.1016/S0140-6736(11)61097-0. [PubMed: 21802134]. [PubMed Central: PMC3285467].

22. Khazaei Z, Goodarzi E, Moradi G. Prevalence of hepatitis B and C in prisons worldwide: A meta-analysis during the years 2005-2015. Biomed Res. 2018;5(4):2235-51. doi:10.15419/bmrat.v5i4.436.

23. Behzadifar M, Gorji HA, Rezapour A, Bragazzi NL. Prevalence of hepatitis $C$ virus infection among prisoners in Iran: A systematic review and meta-analysis. Harm Reduct J. 2018;15(1):24. doi: 10.1186/s12954-0180231-0. [PubMed: 29739400]. [PubMed Central: PMC5941323].

24. Alavian SM. Hepatitis C virus infection: Epidemiology, risk factors and prevention strategies in public health in IR IRAN. Gastroenterology and Hepatology from bed to bench. 2010;3(1).

25. Terrault NA, Dodge JL, Murphy EL, Tavis JE, Kiss A, Levin TR, et al. Sexual transmission of hepatitis $C$ virus among monogamous heterosexual couples: The HCV partners study. Hepatology. 2013;57(3):8819. doi: 10.1002/hep.26164. [PubMed: 23175457]. [PubMed Central: PMC4384338].

26. Shaheen MA, Idrees M. Evidence-based consensus on the diagnosis, prevention and management of hepatitis $\mathrm{C}$ virus disease. World J Hepatol. 2015;7(3):616-27. doi: 10.4254/wjh.v7.i3.616. [PubMed: 25848486]. [PubMed Central: PMC4381185].

27. Azizi A, Amirian F, Amirian M. Prevalence and associated factors of hepatitis C in self-introduced substance abusers. Hayat. 2011;17(1). 